\title{
Solar Photovoltaic Array Reconfiguration for Reducing Partial Shading Effect
}

\author{
Nibras AJ. Khaleel \\ Department of Electronic and Communications Engineering \\ Al-Nahrain University \\ Baghdad, Iraq \\ nbras.abdaljaleel@gmail.com
}

\begin{abstract}
In the photovoltaic (PV) system some problems happen causes a substantial reduction in power generation, one of these problems are Partial shading (PS), and (PS) happen when some obstacles block the sun's rays on the photovoltaic (PV) cells in a PV array, panel, or module in the PV system. Therefore, this paper suggests a method for reducing the effects of partial shading and increasing output power by reconfiguring a solar photovoltaic array using a new shade dispersion strategy (NSDS). The improvements achieved in maximum power point MPP when the shadows are angled or have a significant size, NSDS is also suitable for any photovoltaic array size. The simulation in this study was done by using MATLAB-software Simulink. Different shapes for shades were taken like Short and Wide (SW), Short and Narrow (SN), Long and Wide (LW), and Long and Narrow (LN) partial shading in addition to diagonal shade (DI). The suggested method was used on $6 \times 3$ photovoltaic panels to solve the partial shadow problem that cannot be solved by some previous shadow dispersion methods like so du $\mathrm{Ku}$ and stepwise. Also, it is applied to a $4 \times 2 \mathrm{PV}$ array which is considered difficult to spread the shadows to all PV panels because of its small size. Analysis and comparisons of the output characteristic were done using Cadmium telluride (CdTe) F-4112-3 PV panels and it was found that the increment in the generated power is more than $30 \%$ in comparison with the typical series-parallel (SP) for the SW and LW shades while it is more than $30 \%$ and $20 \%$ in comparison with the Total-Cross-Tied (TCT) configuration for the SW and LW shades respectively.
\end{abstract}

Keywords- PV modules Reconfiguration, stand- alone, partial shading patterns, Shading Effect, MPP

\section{INTRODUCTION}

The interest in the generation of clean energy is increasing in renewables and solar photovoltaic (PV) energy sources, particularly in regions with electric generation troubles [1][2]. Solar PV systems are regarded as an ideal alternative among all renewable energy resources because they are amazingly powerful, have no noise, and are emission-free in nature. However, many factors contribute to reducing electricity generation from Photovoltaic panels like Sun intensity, heat build-up, shading, and dirt. Wherefore, Partial shading is one of the major reasons for the loss of energy [1].

Partial Shading PS is an impact that happens when the radiation on a particular part of a PV array panel or module is obstructed by obstructions, like moving clouds, buildings, or plants The shading solar Cells create less current during the shading conditions. Since the photovoltaic module consists of a series of cells connected in series, the shaded PV cell must supply a similar current as anyone else cell that

\author{
Anas L. Mahmood \\ Department of Electronic and Communications Engineering \\ Al-Nahrain University \\ Baghdad, Iraq \\ anas.lateef.1@nahrainuniv.edu.iq
}

is able to produce more current, under this factor the cells that are shaded behave as a load, sucking energy away from the cells which are unshaded [4]. It is impractical to move the PV array and keep it stays far away from the partial shading in all weather and seasons. So, could be using a PV array connection methodology like Series-Parallel (SP), Total Cross Tied (TCT), Bridge Linked (BL), or Honeycomb (HC) to provides more power and reduces the PS effect [5 8]. The new reconfiguration strategy for shadow dispersion shows that the MPP performed significantly better than the other tested shade dispersion methods such as typical seriesparallel or total-cross-tied configurations even if the shade is wide, or it comes with an angle. The main idea of the suggested new dispersion strategy for reconfiguring PV modules is shown in figure 1 .

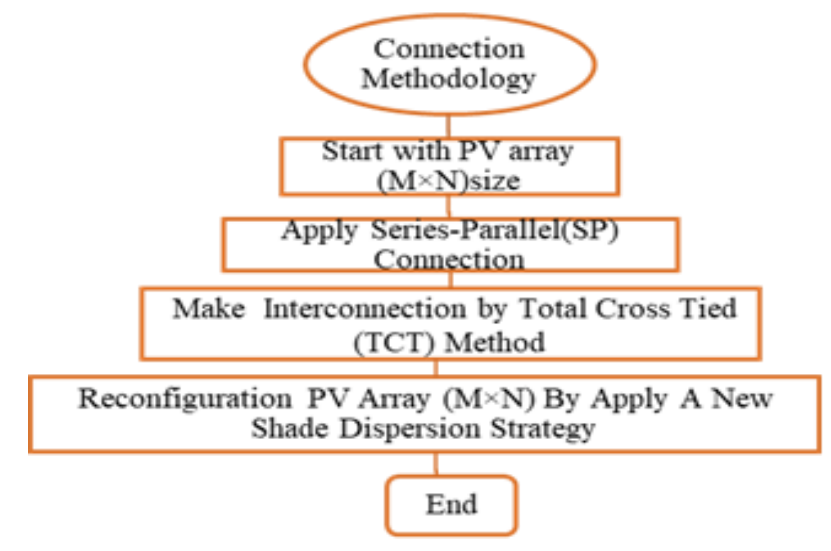

Fig. 1. Steps to improve MPP under PSC for PV system

\section{PhOtovoltaic SYSTEMS AND PV MODULE}

\section{A. Photovoltaic System}

Solar photovoltaic systems are also can be known by component and needed operating procedures, also the parts of energy sources and the electrical loads. The two main classifications of a PV system are the stand-alone PV system which operates independent of the electric utility grid, and The second PV system type is the on-grid PV system that is designed for operation and connection to the electricity supply network [9]. In the stand-alone PV system some Factors affecting on the solar panel efficiency such as sun intensity, heat build-up, shading, and dust. These factors reducing the output power especially when a stand-alone PV system was used. So a stand-alone PV system was taken as an example to solve the partial shading problem with $(2 \times 10$ PV array). The F-4112-3 PV module is used in this 
document is cadmium telluride (CdTe), which has a low temperature and shade damage [2] [10]. The electrical specifications of the CdTe F-4112-3 PV module are illustrated in Table 1.

TABLE I. PV PANEL SPECIFICATION

\begin{tabular}{|c|c|}
\hline $\begin{array}{l}\text { Module Standard Conditions of the CdT } \\
\text { ( irradiance } 1000 \mathrm{w} / \mathrm{M} 2, \mathrm{~T}=25^{\circ} \mathrm{C}, \mathrm{A}\end{array}$ & \\
\hline Nominal Power $6(-0 /+5 \mathrm{~W}) \mathrm{P}_{\mathrm{MPP}}(\mathrm{W})$ & 112.5 \\
\hline Voltage at the $\mathrm{P}_{\mathrm{MAX}}$ & 68.5 \\
\hline Current at the $\mathrm{P}_{\mathrm{MAX}}$ & 1.64 \\
\hline Open Circuit Voltage $\mathrm{V}_{\mathrm{OC}}(\mathrm{V})$ & 87.0 \\
\hline Short Circuit Current $\mathrm{I}_{\mathrm{SC}}(\mathrm{A})$ & 1.83 \\
\hline
\end{tabular}

\section{B. PV module}

In PV systems, the model of a single diode is the most prevalent because of the fewer parameters and the complexity [11]. the photogenerated current (IPV) is created by a Light source, which is link with a diode (DI), a series resistance (Rs), and a parallel resistance $(\mathrm{Rp})$, as illustrated in figure 2.

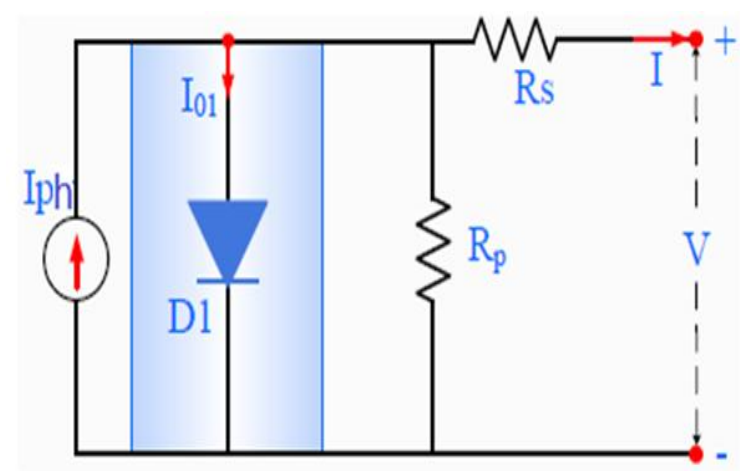

Fig. 2. The circuit Electrical of single diode PV model [12].

\section{SOLAR IRRADIATION AND THE PARTIAL SHADING CONDITION}

The efficiency of a PV system is decreasing due to different factors. Partial shading conditions are a major factor contributing to the loss of power (PSC). Partial shading takes place when a particular part of the PV array strikes at varying irradiance levels, so the PV panel does not receive the necessary amount of irradiance to generate the full value of MPP. wherefore, figure 3 shows MATLAB Simulink for the CdTe PV panel, where $1000 \mathrm{~W} / \mathrm{m} 2$ represents the irradiation from the sun at sea level. The panel generates about $112.5 \mathrm{~W}$ while at $800 \mathrm{~W} / \mathrm{m} 2$, then the power decreases to $83.55 \mathrm{~W}$, and it reaches $10.46 \mathrm{~W}$ when a large portion of the PV panel is shaded with $100 \mathrm{~W} / \mathrm{m} 2$ irradiation.

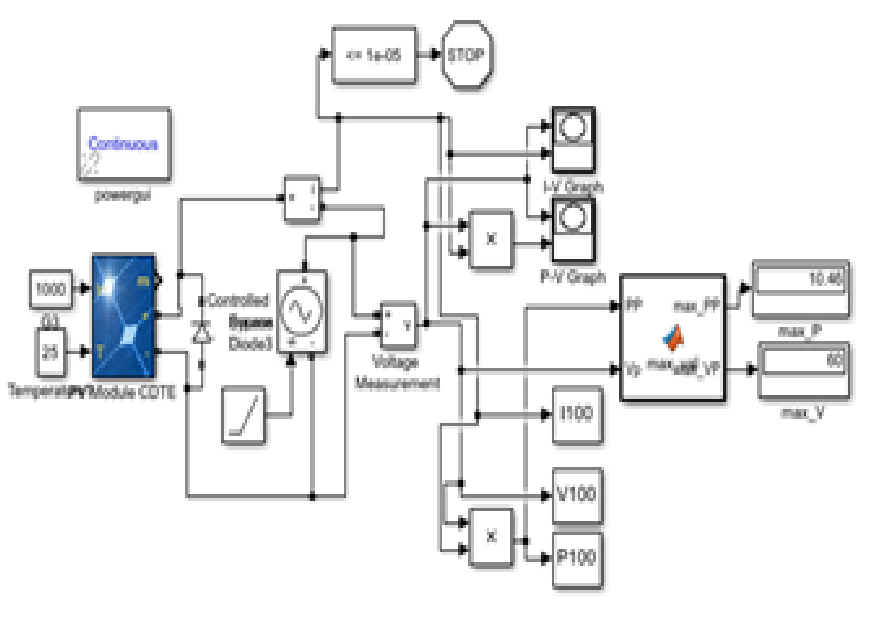

(a)
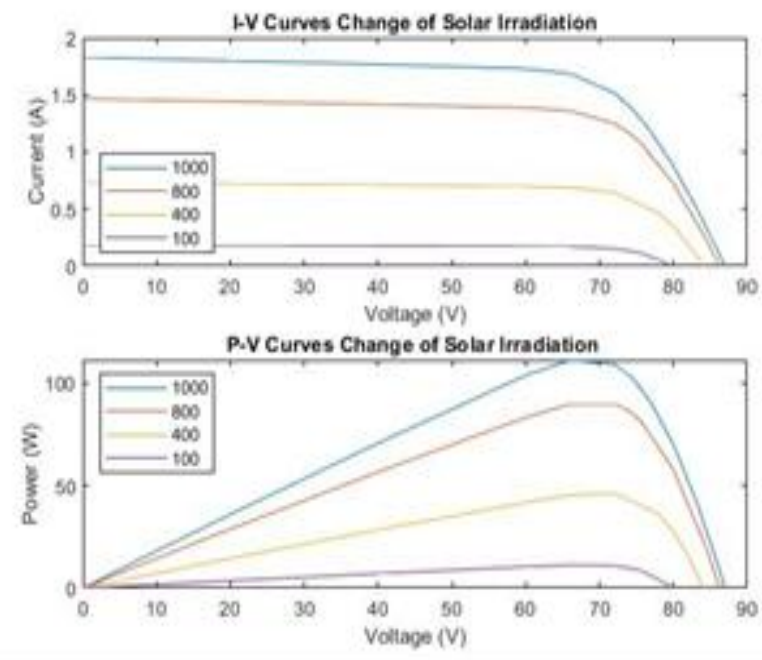

(b)

Fig. 3. (a) Simulink for the CdTe panel. (b)I-V and P-V characteristics.

There are several types of the partial shading condition (PSC) used in this paper, each with a different distribution for the irradiation on a PV system including diagonal (DIA), random (RAN), Short -Narrow (SN), Long-Narrow (LN), Long -Wide (LW), and Short-Wide (SW) [13-15]. figure 4 depicts the distribution of the partial shading pattern types mentioned above.

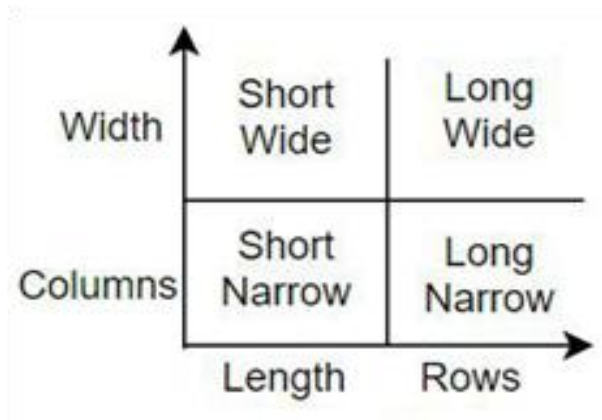

(a) 


\begin{tabular}{|l|l|l|}
\hline 11 & 12 & 13 \\
\hline 21 & 22 & 23 \\
\hline 31 & 32 & 33 \\
\hline 41 & 42 & 43 \\
\hline 51 & 52 & 53 \\
\hline 61 & 62 & 63 \\
\hline
\end{tabular}

(b)

\begin{tabular}{|l|l|l|}
\hline 11 & 12 & 13 \\
\hline 21 & 22 & 23 \\
\hline 31 & 32 & 33 \\
\hline 41 & 42 & 43 \\
\hline 51 & 52 & 53 \\
\hline 61 & 62 & 63 \\
\hline
\end{tabular}

(e)

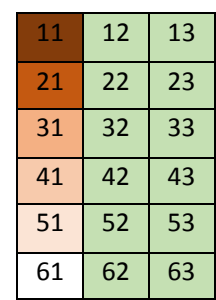

(c)

\begin{tabular}{|l|l|l|}
\hline 11 & 12 & 13 \\
\hline 21 & 22 & 23 \\
\hline 31 & 32 & 33 \\
\hline 41 & 42 & 43 \\
\hline 51 & 52 & 53 \\
\hline 61 & 62 & 63 \\
\hline
\end{tabular}

(f)

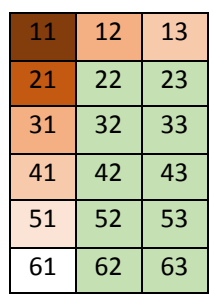

(d)

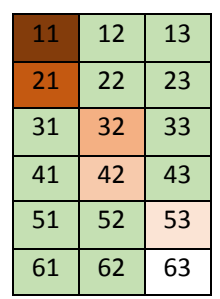

(g)

$1000 \mathrm{~W} / \mathrm{m}^{2} \square 900 \mathrm{~W} / \mathrm{m}^{2} \square 800 \mathrm{~W} / \mathrm{m}^{2} \quad 600 \mathrm{~W} / \mathrm{m}$ $200 \mathrm{~W} / \mathrm{m}^{2}$ $100 \mathrm{~W} / \mathrm{m}^{2}$

Fig. 4. Partial shading pattern types (a) Types of shading patterns (b) No shading (c) LN (d) LW (e) SW (f) SN (g) Diagonal.

\section{PV ARRAY CONNECTION CONFIGURATION}

Changing the solar panel interconnection of a solar power system is one way to decrease the partial shading effect and increase the output power. PV array configurations of various types have been developed. The main configurations Series-Parallel (SP) configuration is the most basic configuration available, when PV modules are connecting in strings form that these strings are connected in a parallel form to increase the total current [16] as figure 5 (a) shown. The second configuration is the Total Cross Tied (TCT) configuration, TCT requires more interconnections than SP configuration due to the inclusion of cross interconnections in SP configuration [6] [16]. Figure 5(b) shows the TCT connection configuration. Another connection is Bridge Linked (BL), BL means "bridge link", inspired by Wheatstone bridge connection as shown in figure 5(c). The final PV system panel configuration shown in figure 5(d) is the Honeycomb (HC) which is short for "honeycomb" and has a pattern similar to a bee comb. According to [17] and [18], the configuration of the TCT photovoltaic module

\section{PV ARRAY RECONFIGURATION}

Another common solution to reduce the partial shading effect is to apply a reconfigurable PV module by using the shade dispersion technique. The thought of shadow dispersion technology is by Physical position rearrangement of the photovoltaic modules in a modified module in some patterns [19] in order to transfer the effect caused by the shadow on the affected module to the other non-shaded parts of the module. There are several shadow dispersion techniques, in this paper, some techniques are used and then compared with the new shadow dispersion reconfiguration strategy (NSDS). The first dispersion technique was Su-Do$\mathrm{Ku}$ reconfiguration, $\mathrm{Su} \mathrm{Do} \mathrm{Ku}$ is a logical puzzle of the number of positions, seems to be combinatorial in origin. In this puzzle for example a $6 \times 6$ or $9 \times 9$ grid would be filled with an integer between 0 and 9 or from 0 to 6 , in every row provides better efficiency and performance under partial shading.

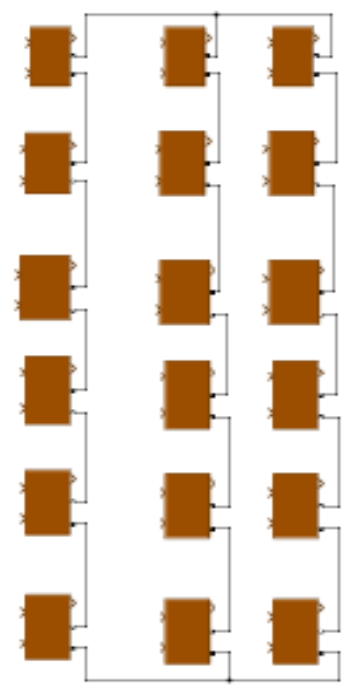

(a)

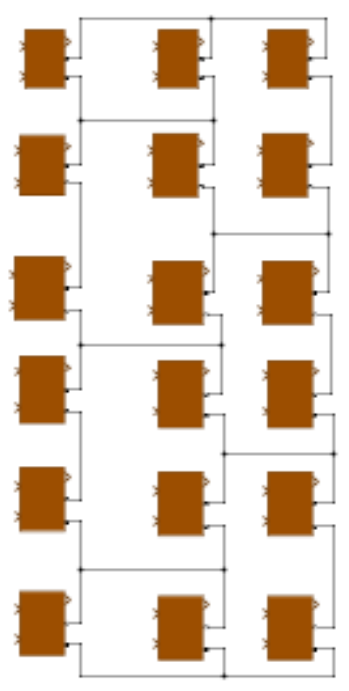

(c)

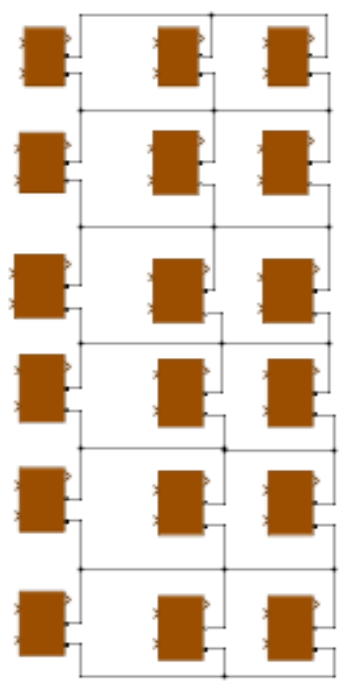

(b)

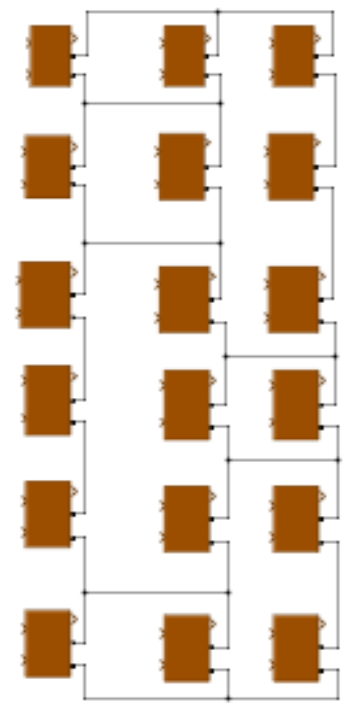

(d)
Fig. 5. (3x6) PV array interconnecting (a) Series Parallel configurations(SP) (b) Total Cross Tied configuration(TCT) (c) Bridge Linked configuration(BL) (d) HoneyComb configuration (HC) or column having just one instance of a particular number. Unfortunately, although PV system with this "random" configuration provides better efficiency as the literature [20] [21] [22] shows, it still Scales limited to $9 \times 9$ array it is also costly and not available for PV systems that have various numbers of columns and rows. The second shade dispersion technique is 'Stepwise', it created by moving the PV panels columns which into a TCT array to bottom by one module relative to its left module counterpart [23]. The stepwise also provide better efficiency but have some weakness, that when the shade is diagonal it is moved to the same rows. The two methods described above are not applicable to all PV array sizes, such as the PV array tested in this study.

The new shade dispersion strategy that used in this research. It is a technique for dispersing and distributing shadows on unshaded solar panels. This method has evolved from an earlier method for dispersing shadows, but the 
previous shade dispersion strategy (PSDS) did not provide a distribution of shades on adjacent panels for the same column.

\section{Mechanism of The new shade dispersion strategy}

$>$ Step1 the PV panels are connected in the SP configuration, and then the TCT interconnection is made.

> Step2 a half of PV array columns that are in a TCT configuration are chosen to moving the PV panels in.

$>$ Step3 PV modules are relocated so, that the shade can evenly disperse from a bottom to the up or mid and the top to the center or bottom of the PV array in the rearranged columns.

The distributing and Simulink of the new shade dispersion strategy for the $3 \times 6 \mathrm{PV}$ array are shown in figures 6 and 7 respectively.

\begin{tabular}{|l|l|l|}
\hline 1 \\
\hline 2 \\
\hline 3 \\
\hline 4 \\
\hline 5 \\
\hline 6 \\
\hline
\end{tabular}$\quad$\begin{tabular}{l|l|}
\hline 1 & 1 \\
\hline 3 & 2 \\
\hline 4 & 4 \\
\hline 5 & 5 \\
\hline 6 & 6 \\
\hline
\end{tabular}

(a)

Fig. 6. $3 \times 6 \mathrm{PV}$ array (a) Original reconfiguration (b) New reconfiguration

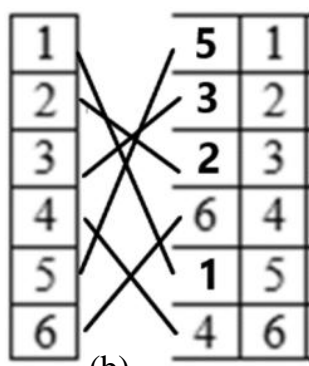

(b)
The MATLAB-Simulink software is used to simulate a photovoltaic array made up of 18 photovoltaic modules in a $3 \times 6$ array as figure 7 shows under all the shapes of shades, the diagonal (DIA), long and narrow (LN), long and wide (LW), short and narrow (SN), and short and wide (SW). The new reconfiguration strategy for shadow dispersion (NSDS) shows that the MPP performed significantly better than the other tested shade dispersion methods, much better than the series-parallel (SP) or the total-cross-tied(TCT) configurations. To illustrate this enhancement in MPP a comparison of the MPP under each PSC is shown in table 2.

TABLE II. MPP FOR CDTE PANELS OF 3X6 PV ARRAY UNDER PS CONDITIONS

\begin{tabular}{|c|c|c|c|c|c|}
\hline & \multicolumn{5}{|c|}{ MPP (W) } \\
\cline { 2 - 6 } & LN & LW & SN & SW & DI \\
\hline SP (3X6) & 1400 & 1087 & 1340 & 1340 & 1302 \\
\hline TCT (3x6) & 1529 & 1147 & 1625 & 1175 & 1457 \\
\hline PSDS (3x6) & 1529 & 1421 & 1734 & 1427 & 1199 \\
\hline NSDS (3x6) & 1508 & 1492 & 1707 & 1585 & 1499 \\
\hline
\end{tabular}

\section{CASE STUdY AND SIMULATION RESUlTS: 4 X 2 CDTE PV PANELS}

Sometimes the location choices are impractical, and shading challenges are common. Additionally, the number of connecting panels and the type of connection are limited by the size of the selected the site. For example, a $4 \times 2$ PV panel using CdTe panels was analyzed using SP, Total-cross-tied (TCT), PSDS, and NSDS reconfiguration strategies. They are simulated under every case of PS (LN, LW, SN, SW, DI) as shown in a figure 8

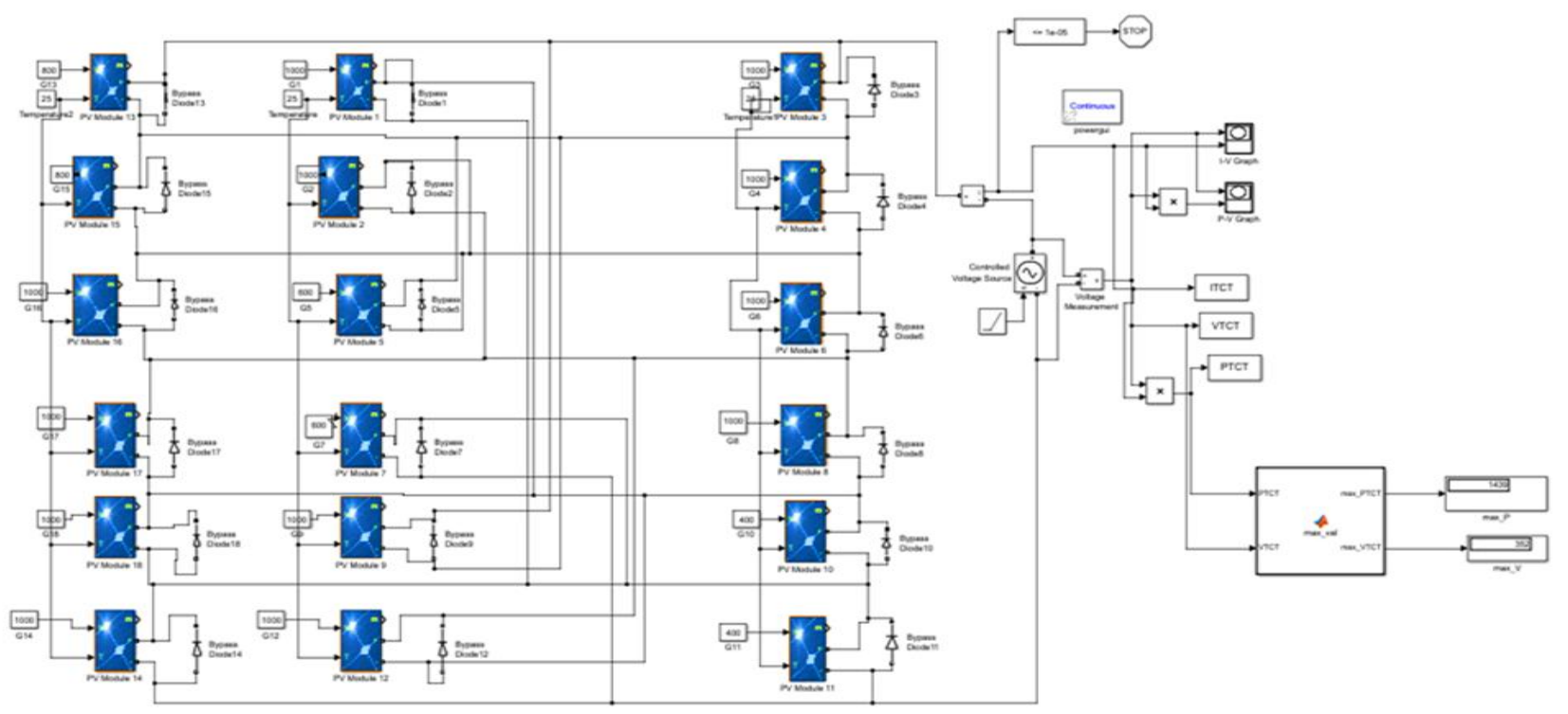

Fig. 7. New Shade Dispersion Strategy MATLAB/Simulink for 3x6 PV array 


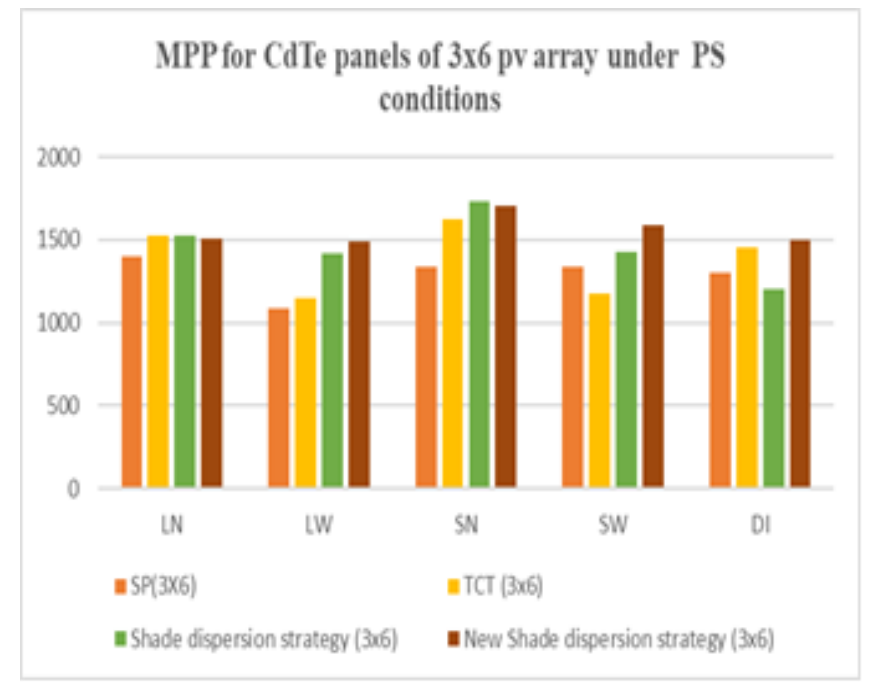

Fig. 8. Analysis MPP for 3x6 PV array.

As mentioned above, this size of solar panel systems which consists of uneven rows and columns cannot solve the problem of partial shading by the previous shade dispersal methods such as the $\mathrm{Su}-\mathrm{do}-\mathrm{Ku}$ or stepwise dispersion method. Therefore, the new shade dispersion strategy can be applied as shown in figure 9 which depicts the MTLABSimulink and PV panel distribution. First, the eight PV panels are linked in series and then in parallel (SP) as $4 \times 2$ PV panels, then the TCT configuration was applied on the panels and finally, the new shade dispersion strategy (NSDS) is applied to two columns. Where panel 2 is rearranged with 6 in the second column and panel 4 is rearranged with 8 in the fourth column. In practice the panels stay in place only the interconnection will change between them. The PV system was tested under various types of partial shading conditions.
Type 1: When short-wide shading effect on some PV panels, such as panels $1,2,3$, and 4 in the first row or on 5, 6,7 , and 8 in the second row. The solar radiations considered are $800 \mathrm{~W} / \mathrm{m}^{2}, \quad 600 \mathrm{~W} / \mathrm{m}^{2}, \quad 400 \mathrm{~W} / \mathrm{m}^{2}$, and $200 \mathrm{~W} / \mathrm{m}^{2}$ respectively as shown in figure 10(a) where the first peak for MPP of NSDS is in yellow color and second red peak for TCT, while the last peak in blue color for SP connection in $\mathrm{P}-\mathrm{V}$ curve and the I-V curve.

Type 2: When short-narrow shadings affect two PV panels, such as panels 1 and 2 in the first row or on 6 and 7 in the second row. The solar radiations considered are $800 \mathrm{~W} / \mathrm{m}^{2}$ and $600 \mathrm{~W} / \mathrm{m}^{2}$ respectively as shown in figure $10(\mathrm{~b})$ where the first peak for MPP of NSDS in yellow color TCT is positioned at the second peak with red color while the last blue peak for SP connection in P-V and I-V curve.

Type 3: When long-wide shading affects some PV panels in the first and second row such as panels 1, 2, 3, and 4 in the first row or on 5 and 7 in the second row. The solar radiations considered are $800 \mathrm{~W} / \mathrm{m}^{2}, 600 \mathrm{~W} / \mathrm{m}^{2}, 400 \mathrm{~W} / \mathrm{m}^{2}$, and $200 \mathrm{~W} / \mathrm{m}^{2}$ respectively as shown in figure 10 (c) the first peak for MPP of NSDS in yellow color TCT which is positioned at the second peak with red color while the last blue peak for $\mathrm{SP}$ connection in $\mathrm{P}-\mathrm{V}$ and $\mathrm{I}-\mathrm{V}$ curve.

Type 4: The last case chooses when long-narrow shading affects some PV panels in the first and second row such as panels 1 and 4 in the first row or on 5 and 7 in a second row. The solar radiations considered are $800 \mathrm{~W} / \mathrm{m}^{2}$ and $600 \mathrm{~W} / \mathrm{m}^{2}$ respectively as shown in figure 10(d) the first peak for MPP of NSDS in yellow color TCT which is positioned at the second peak with red color while the last blue peak for SP connection in $\mathrm{P}-\mathrm{V}$ and $\mathrm{I}-\mathrm{V}$ curve.

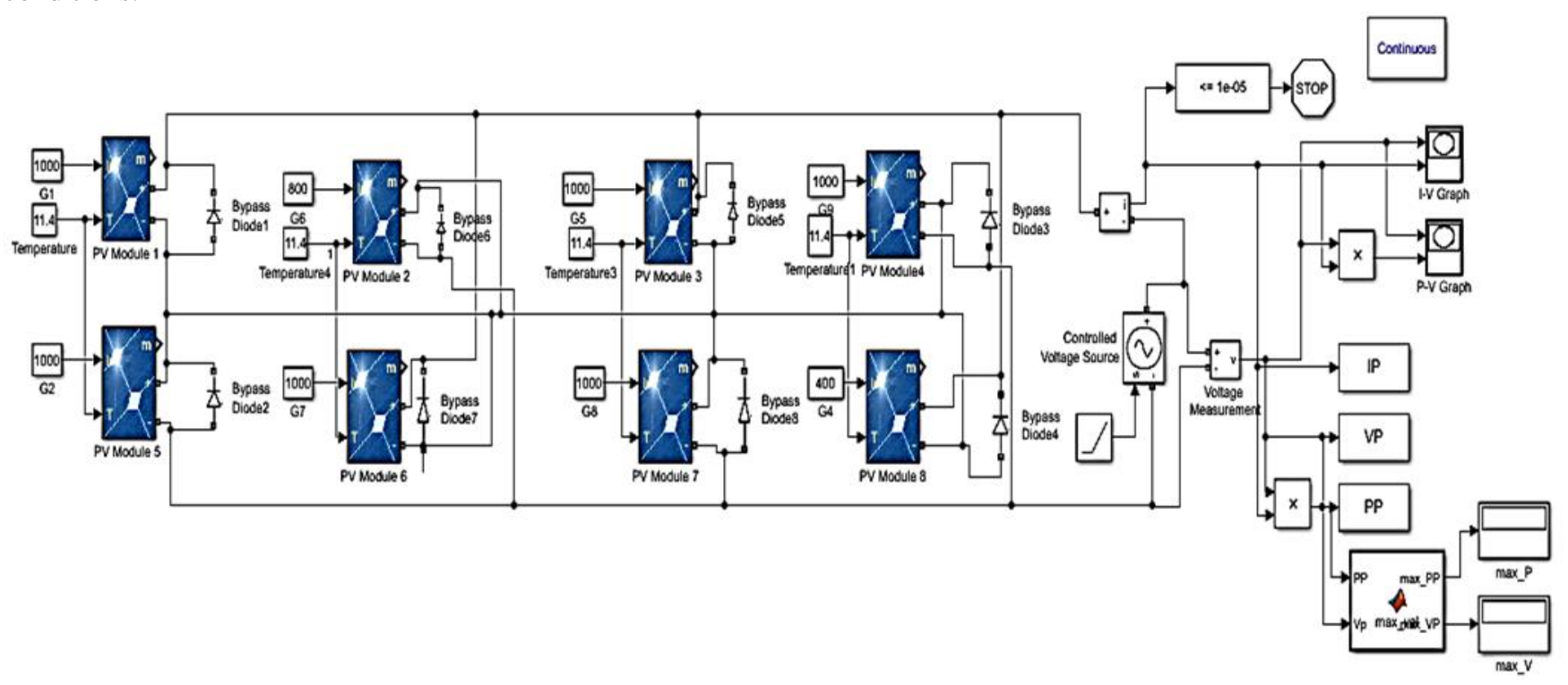

Fig. 9. Matlab Simulink and PV panel distribution for $4 \times 2$ PV array 


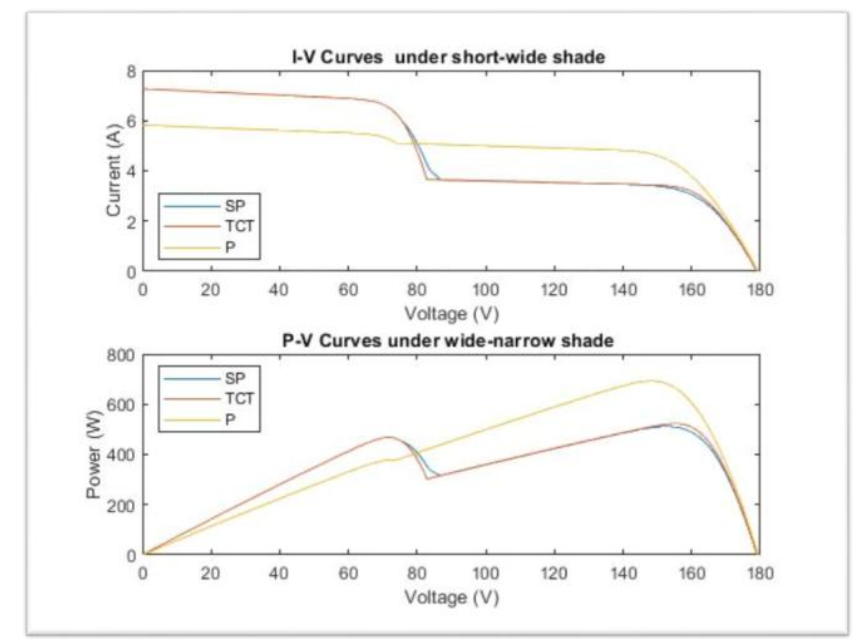

(a) Under short wide shade

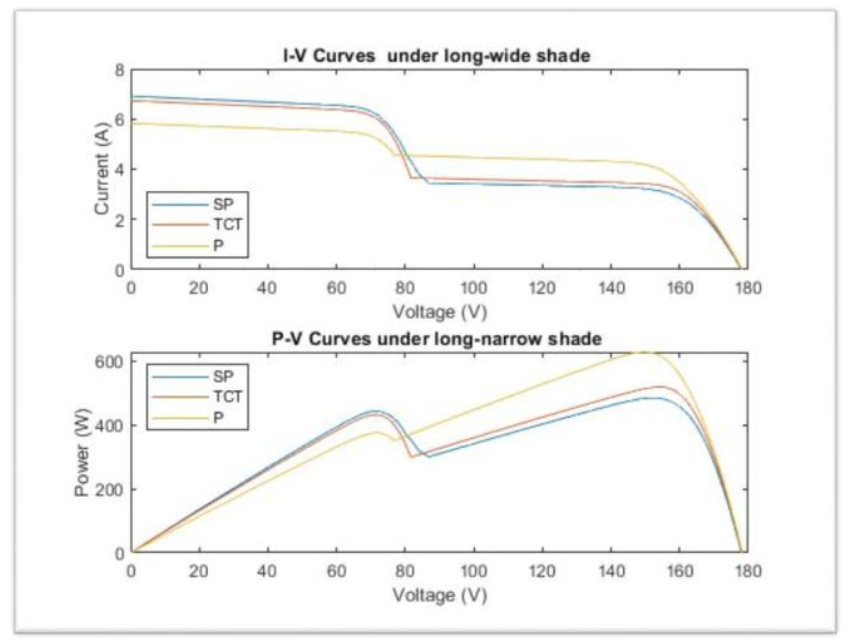

(b) Under long narrow shade

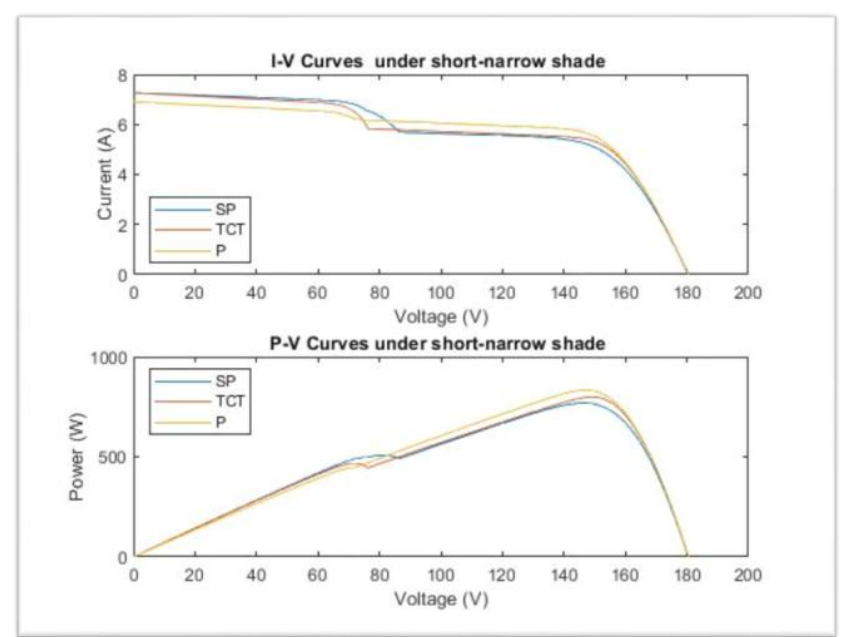

(b) Under short narrow shade

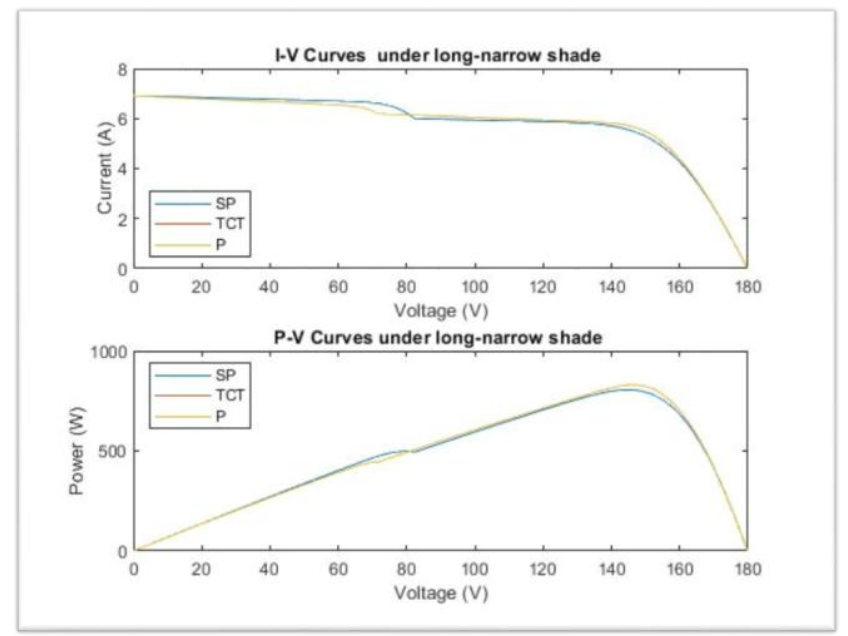

(d) Under long wide shade

Fig. 10. The I-V and P-V curve of various cases for $4 \times 2$ PV panels under partial shading conditions.

The simulation results for $4 \times 2$ PV panels illustrate in table 3 and as seen from the table that the NSDS provides more generated power as SP and TCT. Also table 4 shows the power generated increase percentage in the NSDS in comparison with SP and TCT

TABLE III. THE MPP (W) FOR 4X2 PV PANELS SYSTEM.

\begin{tabular}{|c|c|c|c|c|}
\hline MPP(W) & SN & SW & LW & LN \\
\hline SP & 758 & 488 & 460.9 & 798.3 \\
\hline TCT & 771.7 & 508.7 & 496.1 & 814.6 \\
\hline NSDS & 815.8 & 673.8 & 603.8 & 814.6 \\
\hline
\end{tabular}

TABLE IV. THE GENERATED POWER INCREMENT PERCENTAGE.

\begin{tabular}{|c|c|c|c|c|}
\hline \multirow{2}{*}{} & \multicolumn{4}{|c|}{ NSDS } \\
\cline { 2 - 5 } SP & SN & SW & LW & LN \\
\hline TCT & $6 \%$ & $38 \%$ & $31 \%$ & $2 \%$ \\
\hline
\end{tabular}

\section{CONCLUSIONS}

In this paper, a study was made for the main factor that reducing maximum energy for the solar systems which is partial shading. A solution to this problem was provided by taking into account reducing the cost and complexity of the design as well as avoiding additional electronic circuits or new devices to the system, by relying on the theory of shade dispersal and distributing it on the panels in certain proportions according to the type of shadows that solar system is exposed to. The behavior of TCT, HC, SP, and BL configurations was studied then compared to each other. The TCT configuration was then applied to the system due to its suitability to all system sizes and enhancement to the power. A new shade dispersion strategy was introduced and compared to other shade dispersion techniques. When this technique was applied to a 4x2 PV array system, the output energy was increased obtained about a $30 \%$ increase in the generated power for some cases.

\section{POSSIBLE FUTURE WORK}

Using this rearrangement technique in real applications will become the next step. However, the feasibility of the theory of modularizing various parts of a PV panel during the product manufacturing merits further study, also can take the increasing in temperature problem along the seasons and its effect. 


\section{REFERENCES}

[1] M. Syahir, B. Ishak, R. H. Salimin, I. Musirin, and Z. A. Hamid, "Development of PV array configuration under different partial shading condition," International Journal of Power Electronics and Drive System (IJPEDS) ISSN: vol. 10, no. 3, pp. 1263-1269, 2019, doi: 10.11591/ijpeds.v10.i3.pp1263-1269.

[2] A. L. Mahmood, A. M. Shakir, and B. A. Numan, "Design and performance analysis of stand-alone PV system at al-nahrain university, Baghdad, Iraq," Int. J. Power Electron. Drive Syst., vol. 11, no. 2, pp. 921-930, 2020, doi: 10.11591/ijpeds.v11.i2.pp921-930.

[3] A. Alkholidi and H. Hamam, "Solar Energy Potentials in Southeastern European Countries: A Case Study," Int. J. SMART GRID, vol. 3, no. 2, 2019.

[4] A. M. Ajmal, T. Sudhakar Babu, V. K. Ramachandaramurthy, D. Yousri, and J. B. Ekanayake, "Static and dynamic reconfiguration approaches for mitigation of partial shading influence in photovoltaic arrays," Sustain. Energy Technol. Assessments, vol. 40, no.22. April, p. 100738,2020 , doi: 10.1016/j.seta.2020.100738.

[5] V. P. Madhanmohan, M. Nandakumar, and A. Saleem, "Enhanced performance of partially shaded photovoltaic arrays using diagonally dispersed total cross tied configuration," Energy Sources, Part A Recover. Util. Environ. Eff., vol. 42, no. 1, pp. 1-19, 2020, doi: $10.1080 / 15567036.2020 .1826008$.

[6] H. Rezk, A. Fathy, and M. Aly, "A robust photovoltaic array reconfiguration strategy based on coyote optimization algorithm for enhancing the extracted power under partial shadow condition," Energy Reports, vol. 7,no.5 pp. 109-124, 2021, doi:10.1016/j.egyr.2020.11.035.

[7] R. K. Pachauri, B. Khan, J. Bai, I. Kansal, and O. P. Mahela, "Shade dispersion methodologies for performance improvement of classical total cross-tied photovoltaic array configuration under partial shading conditions," no. February, pp. 1796-1811, 2021, doi: $10.1049 /$ rpg2.12147.

[8] M. K. Mishra and V. N. Lal, "An improved methodology for reactive power management in grid integrated solar PV system with maximum power point condition," Sol. Energy, vol. 199, no.8, September 2019, pp. 230-245, 2020, doi: 10.1016/j.solener.2020.02.001.

[9] V. Fthenakis, C. Athias, A. Blumenthal, A. Kulur, J. Magliozzo, and D. Ng, "Sustainability evaluation of CdTe PV: An update," Renew. Sustain. Energy Rev., vol. 123, no. December 2019, p. 109776, 2020, doi: 10.1016/j.rser.2020.109776.

[10] A. Rai, "Modeling Of Photovoltaic Cell and Study Partial Shading Effect Using Matlab / Simulink," international journal of innovatıve technology and creative engineering (issn:2045-8711) vol.6 no.9 september 2016, 1mpact factor:0.61 no. May, 2017.

[11] D. Yousri, T. S. Babu, E. Beshr, M. B. Eteiba, and D. Allam, "A Robust Strategy based on Marine Predators Algorithm for large scale Photovoltaic array reconfiguration to Mitigate the Partial Shading Effect on the Performance of PV System," IEEE Access ,vol.8,no.25,2020,doi:10.1109/ACCESS.2020.3000420.

[12] A. I. Nusaif and A. L. Mahmood, "MPPT Algorithms ( PSO , FA, and MFA ) for PV System Under Partial Shading Condition, Case
Study: BTS in Algazalia , Baghdad," international journal of smart grid, vol.4, no.3, September, 2020.

[13] S. R. Pendem and S. Mikkili, "Modelling and performance assessment of PV array topologies under partial shading conditions to mitigate the mismatching power losses," Sol. Energy, vol. 160, no.39. November 2017, pp. 303-321, 2018, doi: 10.1016/j.solener.2017.12.010.

[14] D. Prince Winston, S. Kumaravel, B. Praveen Kumar, and S. Devakirubakaran, "Performance improvement of solar PV array topologies during various partial shading conditions," Sol. Energy, vol. 196, no.45, July 2019, pp. 228-242, 2020, doi: 10.1016/j.solener.2019.12.007.

[15] S. Sharma et al., "Performance Enhancement of PV System Configurations Under Partial Shading Conditions Using MS Method," IEEE Access, vol. 9,no.2,2021, doi: 10.1109/ACCESS.2021.3071340.

[16] V. P. Madhanmohan and M. Nandakumar, "Effects of Partial Shading in Different PV module Configurations with Minimum Interconnections,” 2018 Int. Conf. Power, Instrumentation, Control Comput., no.5, pp. 1-6, 2018.

[17] V. B. Raju and C. Chengaiah, "A Novel T-C-T Solar Photovoltaic Array Configurations using Rearrangement of PV Modules with Shade Dispersion Technique for Enhancing the Array Power," International Journal of Recent Technology and Engineering (IJRTE) ISSN: $2277-3878$, Vol-8 no. 5, pp. 68-78, 2020, Issue-5S, February 2020,doi: 10.35940/ijrte.E1018.0285S20.

[18] G. Noida, "Experimental Analysis of SPI TCT PV Array Configurations under Partial Shading Conditions 123 , , IEEE 1st International Conference on Power Electronics, Intelligent Control and Energy Systems (ICPEICES), no. 2, pp. 0-5, 2016.

[19] P. Livreri, M. Caruso, V. Castiglia, F. Pellitteri, and G. Schettino, "Dynamic Reconfiguration of Electrical Connections for Partially Shaded PV Modules: Technical and Economical Performances of an Arduino-Based Prototype," vol. 8, no. 1, 2018.

[20] G. Sagar, D. Pathak, P. Gaur, and V. Jain, "A Su Do Ku puzzle based shade dispersion for maximum power enhancement of partially shaded hybrid bridge-link-total-cross-tied PV array," Sol. Energy,vol. 204, no.March,pp.161-180, 2020, doi: 10.1016/j.solener.2020.04.054.

[21] B. Si, A. Nadia, Z. Nora, B. Nadia, and M. Ahmed, "New Sudoku PV Array Configuration for Out Put Power Losses Minimization," International Journal Natural and Engineering Sciences (IJNES), vol. 13, no. 2, pp. 59-62, 2019.

[22] C. L. Chaw, "An Approach To Reduce the Effect of Partial Shading on," University of British Columbia, August, 2012, [Online].Available:https://open.library.ubc.ca/cIRcle/collections/ubct heses/24/items/1.0166669.

[23] H. S. Sahu, "Power Enhancement of Partially Shaded PV Array by Using a Novel Approach for Shade Dispersion," IEEE Innovative Smart Grid Technologies - Asia (ISGT Asia),pp. 498-503, 2014. DOI: 10.1109/ISGT-Asia.2014.6873842 